EESTI NSV TEADUSTE AKADEEMIA TOIMETISED 4954. III kd., nr. 3 ИЗВЕСТИЯ АКАДЕМИИ НАУК ЭСТОНСКОИ ССР 1954. Том III, 주 3

\title{
ПРИЛОЖЕНИЕ РЕШЕНИЯ ЗАДАЧИ ПЕРЕМЕШИВАНИЯ СТРУИ ВОЗДУХА В ПОПЕРЕЧНОМ ПОТОКЕ К РАСЧЕТУ ГАЗОВЫХ ГОРЕЛОК
}

\author{
Ю. В. ИВАНОВ, \\ кандндат технических наук
}

Расширение газификации городов сопровождается увеличением потребления газа не только для бытовых целей, но и в целом ряде промышленных объектов. При этом большое значение приобретают вопросы

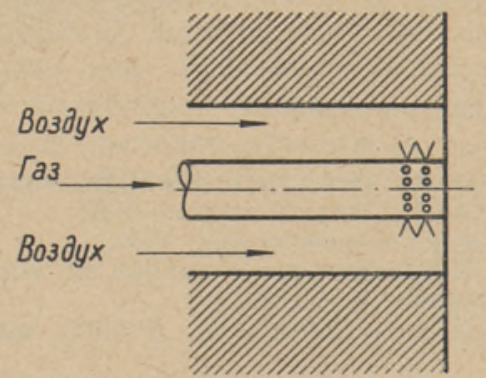

Фиг. 1. Схема газовой горелки.

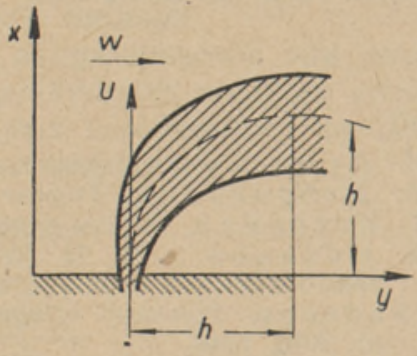

Фиг. 2. Схема струи в потоке.

рационального конструирования горелочных устройств. В этой связи необходимо приветствовать появление выполненной в Институте теплоэнергетики АН УССР работы И. И. Чернобыльского и Г. М. Щеголева $\left({ }^{9}\right)$, посвященной расчету промышленных газовых горелок с воздушным дутьем, сконструированных по схеме, изображенной на фиг. 1.

В таких горелках газ выходит из отверстий в круглой трубе. Струи газа проникают в поток подаваемого по кольцевому каналу воздуха и образуют с ним горючую смесь (фиг. 2).

Работа И. И. Чернобыльского и Г. М. Щеголева приобретает тем большее значение, что в литературе до сих пор отсутствовали данные для расчета горелок с предварительным перемешиванием газа и воздуха. В этих горелках применяются как круглые, так и щелевидные отверстия. В указанной выше работе $\left({ }^{9}\right)$ рассматривались горелки с круглыми отверстиями, чаще всего встречающиеся на практике. Исходя из этого, И. И. Чернобыльский и Г. М. Щеголев поставили в первую очередь задачу исследования распространения круглой струи в поперечном, по 
отношению к начальному направлению ее, потоке и установления закономерностей, характерных для такого процесса. Выяснение механизма взаимодействия струи с потоком позволит рассчитать процесс перемешивания газа с воздухом и, таким образом, обеспечит полное и достаточно короткофакельное сгорание газа, так как работами ряда исследователей $(2,4,10)$ доказано, что для сжигания газа достаточно осуществить полное его перемешивание с воздухом.

Постановка опытов И. И. Чернобыльским и Г. М. Щеголевым и результаты их исследования не вызывают возражений и дают весьма ценный экспериментальный материал. Однако с расчетными формулами и основанной на них методикой расчета горелок нельзя согласиться.

В настоящей статье делается попытка развить методику расчета горелок не только с круглыми, но и с прямоугольными отверстиями для взаимодействующих потоков одинаковой и разной плотности.

\section{Постановка вопроса}

Чисто аналитическое решение вопроса о закономерностях распространения струи во внешнем поперечном потоке встречает пока непреодолимые трудности. Однако из основных дифференциальных уравнений И. И. Чернобыльский и Г. М. Щеголев сделали вывод, что процесс смешения может быть охарактеризован критерием подобия гомохронности $(H o)$ и критерием Рейнольдса $(R e)$. Для исключения времени из окончательных формул они рассматривают такую точку, для которой критерни гомохронности для струи и для потока равны между собой. При этом условии задача сводится к определению дальнобойности струи (выраженной в виде $\frac{h}{d}$ в относительных величинах) посредством некоторой зависимости

$$
\frac{h}{d}=f\left(R e_{u}, R e_{w}\right)
$$

где $h$ - расстояние от плоскости выхода до рси струи, принявшей направление движения потока;

$$
\begin{aligned}
& d \text { - диаметр струи в устье; } \\
& R e_{u} \text { - критерий Рейнольдса струн; } \\
& R e_{w}-\text { критерий Рейнольдса потока. }
\end{aligned}
$$

Для установления вида этой зависимости были поставлены опыты по исследованию истечения водяной струи в прозрачный, прямоугольной формы канал сечением $75 \times 50$ мм и длиной 570 мм, по которому протекал поток, являющийся для струи поперечным. Вода, вытекавшая в виде струи, предварительно окрашивалась. При помощи нанесенной на стенках прозрачного канала сетки можно было установить профиль струи в двух взаимно перпендикулярных проекциях.

Такие изображения струи вычерчивались для каждого опыта отдельно. Одно из них представлено на фиг. 3.

Опыты проводились при различных диаметрах сопел и различных скоростях струи и поперечного потока.

Зависимость вида (1) предполагалась степенной;

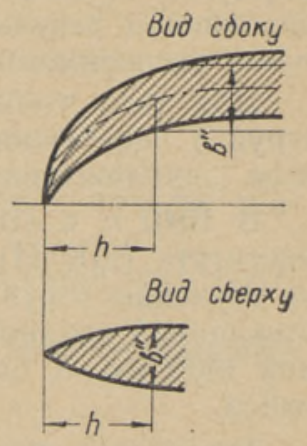

Фиг. 3. Контуры струи в потоке в двух проекциях. 
в этом случае обработка результатов опытов

сводилась в основном к определению постоянных $C, m$ и $n$ в уравнении

$$
\frac{h}{d}=C \operatorname{Re}_{u}^{m} \operatorname{Re}_{w}^{n} .
$$

Значения $h$ определились из опыта в соответствии с фиг. 2. При вычислении критериев $R e_{u}$ и $R e_{w}$ в качестве определяющего размера был принят диаметр сопла.

В результате обработки был получен окончательный вид формулы для определения относительной дальнобойности струи:

$$
\frac{h}{d}=12 \frac{R e_{u}^{1,3}}{R e_{w}^{1,625}}
$$

По нашему мнению, описанная постановка вопроса и полученная расчетная формула не могут не вызвать серьезных возражений. Рассматриваемый процесс относится к такого рода явлениям, в которых молекулярная вязкость не имеет существенного значения. В связи с этим подобные явления (свободные турбулентные струи, турбулентные струи во внешних потоках) автомодельны относительно чисел $R e$. В этом случае, как было показано в нашей работе $\left({ }^{3}\right)$, для траекторий круглых струй во внешнем потоке решающим является отношение количеств движения секундного расхода внешнего потока и струи в устье, или соотношение их скоростных напоров.

Следует заметить, что этот параметр должен входить в число определяющих даже и в том случае, когда нет автомодельности относительно критерня $R e$ (ламинарные струи). В связи с этим зависимость (1) вообще не является полной.

Не останавливаясь более подробно на теоретической стороне рассматриваемого вопроса, покажем, что результаты опытов указанных выше исследователей вполне согласуются как с нашими данными, так и с принятой нами обработкой опытных данных (исходящей из автомодельности процесса в отношении $R e$ ).

C экспериментальной точки зрения также неубедительна приведенная в работе $\left({ }^{9}\right)$ обработка материала, включающая $R e$, так как влияние вязкости в опытах не проверялось.

Поэтому сами по себе верные опыты интерпретированы неудаччной формулой и, следовательно, расчеты по этой формуле не могут давать правильных результатов для случаев, отклоняющихся от условий постановки экспериментов.

Для того чтобы глубже разобраться в вопросе о распространении струи в поперечном потоке, обратимся предварительно к опытным данным, опубликованным в литературе.

В 1940 г. в Центральном научно-исследовательском котлотурбннном институте (ЦКТИ) проводилась первая экспериментальная работа $(5,6)$ по изучению струй в поперечном потоке. Опыты проводились на плоской стеклянной водяной модели с поперечным сечением $600 \times 48$ мм и длиной 1400 мм. К одной из узких сторон модели присоединялись съемные сопла.

Траектории струй изучались по фотографиям. Средняя линия, проведенная на равном расстоянии от наружной и внутренней границ струи, давала ось струи. В результате проведенного исследования была полу- 
чена расчетная формула для определения максимальной дальнобойности струй *:

$$
\frac{h}{d}=k \frac{v_{2}}{v_{1}} \sqrt{\frac{T_{1}}{T_{2}}}
$$

В 1952 г. почти одновременно были опубликованы две работы, проведенные различными методами. Вторая работа $\left({ }^{3}\right)$ также проводилась в ЦКТИ, но пө совершенно другой методике.

Третьей работой является описанное выше исследование, проведенное в Институте теплоэнергетики АН УССР.

В этой работе $\left({ }^{9}\right)$ приводятся сравнения с первым исследованием ЦКТИ, причем результаты исследования обеих работ не совпадают между собой. Интересно сделать сопоставление всех трех работ.

Для этого ознакомимся вкратце с постановкой второго исследования, проведенного в ЦКТИ $\left({ }^{3}\right)$. Работа была задумана как продолжение первого исследования с целью проверки расчетных рекомендаций для неизотермических потоков. Постановка исследования диктовалась необходимостью получения данных для расчета дутья в топках, расчета воздушных завес, смесительных устройств и других технических случаев, в которых имеет место взаимодействие неизотермических потоков различной скорости. Ставилась, в первую очередь, задача получения расчетных рекомендаций по острому дутью применительно к схеме, аналогичной изображенной на фиг. 2.

При постановке исследования было учтено, что опыты со свободными турбулентными изотермическими струями, проведенные различными исследователями, до значений $R e=8 \cdot 10^{6}$ подтверждают теоретически ожидаемую автомодельность явления в отношении критерия $R e$.

Для неизотермического истечения определяющим является критерий Архимеда $(A r)$. Для струй острого дутья в топках критерий $A r$ имеет значения меньшие, чем 0,005. В работе Д. Н. Ляховского и С. Н. Сыркина $\left({ }^{7}\right)$ экспериментально показано, что при значении критерия $A r$ меньше 0,005 влияние его на траекторию струи практически ничтожно.

При исключении влияния критериев $R e$ и $A r$ траектории струй острого дутья следует поставить в зависимость от

1) формы устья сопла,

2) ориентации сопла по отношению к направлению потока (прямоугольное сопло можно поставить большей или меньшей стороной перпендикулярно направлению потока),

3) угла атаки струи $\alpha$,

4) коэффициента структуры струи $a$,

5) параметра $\frac{\varrho_{1} v_{1}^{2}}{\varrho_{2} v_{2}^{2}}$.

Безразмерный параметр $\frac{\varrho_{1} v_{1}^{2}}{\varrho_{2} v_{2}^{2}}$ является соотношением количеств движения секундного расхода внешнего потока и струи в устье, или соотношением их скоростных напоров.

Влияние этого параметра предполагалось проверить при последующей обработке экспериментального материала.

* Под дальнобойностью струи в этой работе, так же как в работе $\left({ }^{9}\right)$, понимается расстояние по нормали от устья до плоскости, в которой изогнутая в начале струя выходит в конечном счете на вертикаль, отвечающую направлению потока. 
Представляло также интерес определить экспериментально величину дальнобойности струи $D_{1}$. Дальнобойность струи $D_{1}$, понимаемая как относительное расстояние $\frac{x}{d}$ по нормали от плоскости устья до места струи, в котором проекция осевой скорости на ось $x$ составляла $5 \%$ устьевой скорости, определялась для круглых струй в виде:

$$
D_{1}=f\left(a, a, \frac{\varrho_{1} v_{1}^{2}}{\varrho_{2} v_{2}^{2}}\right) .
$$

Опыты проводились на воздушной модели. В вертикальном канале сечением $480 \times 600$ мм создавался внешний поток с неравномерностью скоростей $\pm 5 \%$. В этот поток через сопло круглой или прямоугольной формы подавалась воздушная струя. Под воздействием внешнего потока струя на пути своего движения изгибалась. Диаметры выходных сечений круглых сопел были приняты 5,10 и 20 мм. Площади выходных сечений круглых и прямоугольных (с отношением сторон 1:5) сопел были соответственно равны. С одной стороны внешний поток ограничивался фронтовой стеной высотой 1250 мм, служившей местом установки сопел.

В работе были исследованы дальнобойности струй, их траектории, a также изменения скоростей и температур вдоль осей струй.

В результате исследования было установлено, что дальнобойность $D_{1}$ как изотермических, так и неизотермических струй может определяться по формуле

$$
D_{1}=k_{1} \frac{v_{2}}{v_{1}} \sqrt{\frac{\varrho_{2}}{\varrho_{1}}}
$$

где $k_{1}$ - безразмерный опытный коэффициент.

Для круглых струй с углом атаки $\alpha=90^{\circ}$ при коэффициенте структуры $a=0,06$ имеем $k_{1}=2$.

Для выявления влияния коэффициента структуры $a$ на дальнобойность проводились дополнительно опыты со струями, имеющими значения $a=0,065$ и 0,08 .

В результате этих опытов была получена формула для расчета дальнобойности струй «естественной турбулентности» при любых значениях коэффициента структуры в виде:

$$
a D_{1}=k_{2} \frac{v_{2}}{v_{1}} \sqrt{\frac{\rho_{9}}{\varrho_{1}}},
$$

где $k_{2}$ - безразмерный опытный коэффициент. Для круглых струй с углом атаки $\alpha=90^{\circ}$ имеем $k_{2}=0,12$. Зависимости $k_{1}$ и $k_{2}$ от углов атаки даны в работе $\left({ }^{3}\right)$.

Дальнобойности по трем экспериментальным работам сопоставлены на фиг. 4, на которой видно, что экспериментальные точки, характеризующие дальнобойность струй, полученные во второй работе ЦКТИ и в работе Института теплоэнергетики АН УССР, хорошо совпадают между собой. Данные первого исследования ЦКТИ не совпадают с данными двух других указанных выше работ, а дают преуменьшенные значения дальнобойностей.

Это расхождение объясняется различием размеров каналов в сравниваемых опытах. Опыты Д. Н. Ляховского проводились в узком канале, причем на расширение струи влияли боковые стенки и увеличение скорости потока вследствие загромождения сечения канала струей. В нашей работе $\left({ }^{3}\right)$ на это обстоятельство указывалось, и специально поставлен ными опытами было показано, при каких значениях величины $\frac{B}{d}$ (отно- 
шения ширины канала к диаметру струи в устье) сказывается влияние боковых стенок на траекторию струи. Кроме того, было высказано предположение, что струя в узком канале загромождает часть сечения, а в остальной его части происходит перестройка скоростного поля, приводящая к увеличению средней скорости потока.

На фиг. 4 нанесена, согласно уравнению (6), пунктирная прямая $(-\cdots)$, которая характеризует значения дальнобойностей струй $D_{1}$. Уравнение (6) дает меньшие значения дальнобойностей, чем это можно определить по экспериментальным точкам, соответствующим продолжению осей затухающнх струй. Это расхождение закономерно, и оно выте-

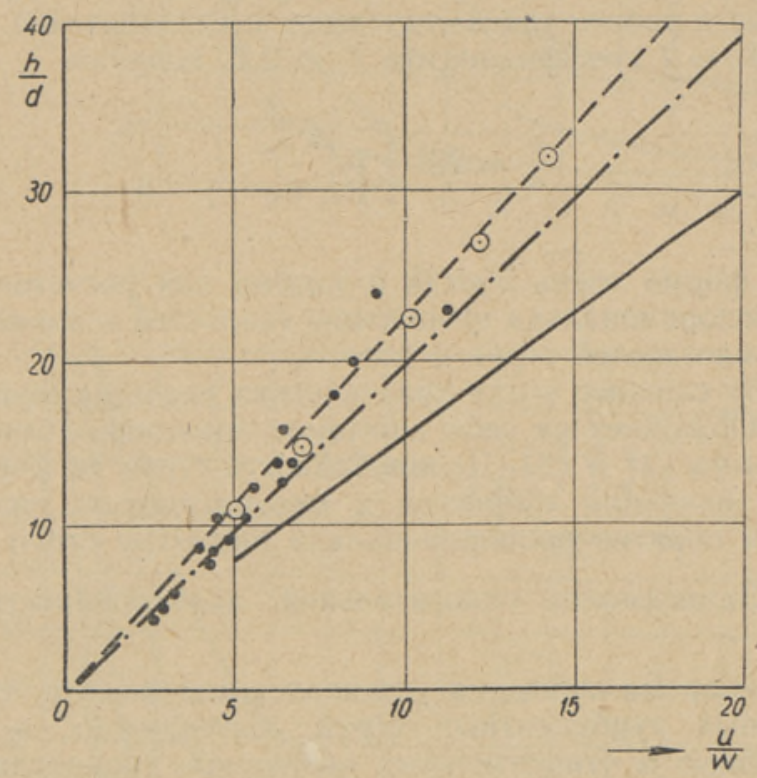

Фиг. 4. Сопоставление дальнобойностей по трем экспериментальным работам.

구의 И. И. Чернобыльского и Г. М. Щеголева.

- Дальнобойность $\frac{h}{d}$, подсчитанная по формуле (4) Д. Н. Дяховского.

- - Дальнобойность $\frac{h}{d}$, подсчнтанная по формуле (8)

○ Опыты автора.

кает из самого определения дальнобойности $D_{1}$. Количественное значение расхождения составляет около $10 \%$. Если надо подсчитать максимальную дальнобойность струи, понимаемую как относительное расстояние от устья до оси струи, принявшей направление потока, то можно рекомендовать то же уравнение (6), но тогда при $\alpha=90^{\circ}$ вместо прежнего значения $k_{1}=2$ нужно взять коэффициент $k_{1}=2,2$. Для расчета струй острого дутья нами в работе $\left({ }^{3}\right)$ принималась не максимальная дальнобойность струй $h$, которая не так существенна для характеристики полного перемешивания струй с потоком при углах $a>90^{\circ}$, а дальнобойность струй $D_{1}$. В данном случае для струй с углом $\alpha=90^{\circ}$ можно воспользоваться максимальной дальнобойностью $h$. 
Приведенное на фиг. 4 сравнение показывает, что результаты двух экспериментальных работ между собой хорошо совпадают, а рекомендуемые расчетные формулы существенно различаются. Для наглядности развернем формулу (3), рекомендованную И. И. Чернобыльским и Г. М. Щеголевым:

$$
\frac{h}{d}=12 \frac{R e_{n}^{1,3}}{R e_{w}^{1,625}}=12 \frac{u^{1,3} d^{1,3} \cdot v_{w}^{1,625}}{v_{t}^{1,3} \cdot w^{1,625} \cdot d^{1,625}}
$$

и сравним ее с рекомендованной нами формулой (6) или, вводя обозначения, принятые в работе указанных выше исследователей $\left({ }^{9}\right)$, и заменив коэффициент $k_{1}=2$ коэффициентом $k_{1}=2,2$, получим

$$
\frac{h}{d}=2,2 \frac{u}{w} \sqrt{\frac{\varrho_{u}}{\varrho_{w}}} .
$$

Последняя форма очень проста и удобна для расчетов. Дальнобой. ность струи пропорциональна отношению скоростей и корню квадратному из отношения плотностей струи и потока.

Формула (3) сложнее и для практических расчетов менее удобна, чем формула (8). Обращает на себя внимание принципиальное расхождение между формулами (3) и (8). Дальнобойность струи по формуле (3) пропорциональна значениям скоростей и кинематических вязкостей в разных степенях и обратно пропорциональна диаметру струи в устье в степени 0,325 . Зависимость относительной дальнобойности $\frac{h}{d}$ от $d^{0,325}$ непонятна.

В настоящее время считается установленным фактом, что все закономерности круглых турбулентных струй, вытекающих в неподвижную среду, выраженные в относительных величинах, справедливы для струй любых диаметров.

В нашем исследовании $\left({ }^{3}\right)$ показано, что закономерности круглых турбулентных струй, вытекающих во внешний поперечный поток, выраженные в относительных величинах, также остаются верными для струй различных диаметров.

Это, в свою очередь, означает, например, что относительная дальнобойность струй $\frac{h}{d}$ в подобных процессах должна. оставаться постоянной и для струй любых диаметров и, следовательно, не будет зависеть от диаметра.

Поскольку формула (8) принципиально отличается от формулы (3), то ознакомимся также с опытами и обработкой опытных данных во второй работе ЦКТИ $\left({ }^{3}\right)$.

Опыты проводились во внешнем поперечном потоке со струями диаметром в устье 5,10 и 20 мм при отношениях скоростей $\frac{v_{2}}{v_{1}}=5,10$ и 20 . Опыты проводились как с изотермическими, так и неизотермическими потоками, причем отношения плотностей $\frac{\varrho_{1}}{\varrho_{2}}$ были 0,$64 ; 0,67 ; 1 ; 2$ и 2,86 .

На фиг. $5, a$ и 5,6 показано, что изменения относительных разностей скоростей $\frac{v_{m}-v_{1}}{v_{0}-v_{1}}$ круглых струй различных диаметров вдоль осей в за- 

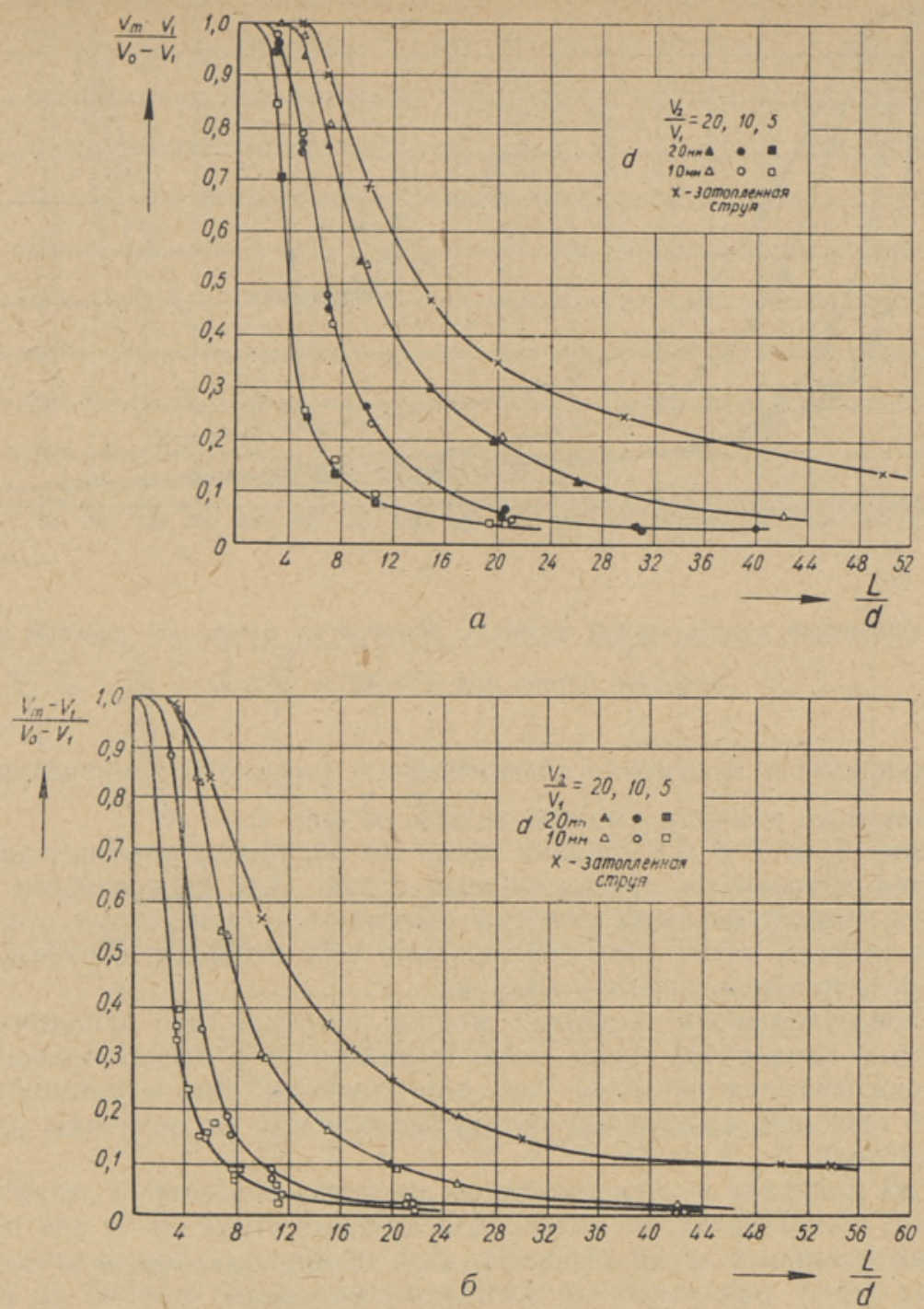

Фиг. 5. Изменение относительной разности скоростей вдоль оси круглой струи во внешнем потоке при $a=90^{\circ}$;

$$
a-\text { при } \frac{T_{2}}{T_{1}}=1, \quad б-\text { при } \frac{T_{2}}{T_{1}}=2 .
$$

висимости от $\frac{L^{*}}{d_{\vartheta}}$ при прочих равных условиях характеризуются единой кривой. Так, например, все экспериментальные точки подобных между собой опытов со струями 10 и 20 мм укладываются на единую кривую. Таких кривых несколько; каждая из них соответствует различному соотношению скоростей.

Опытные точки, полученные при диаметре струи 5 мм, легли на те же кривые, но для избежания перегрузки кривых точками, они не нанесены.

* $L$ - расстояние вдоль оси струи, $v_{0}$ - максимальная скорость струи в устье, $v_{m}$ - максимальная скорость в ноперечных сечениях. 


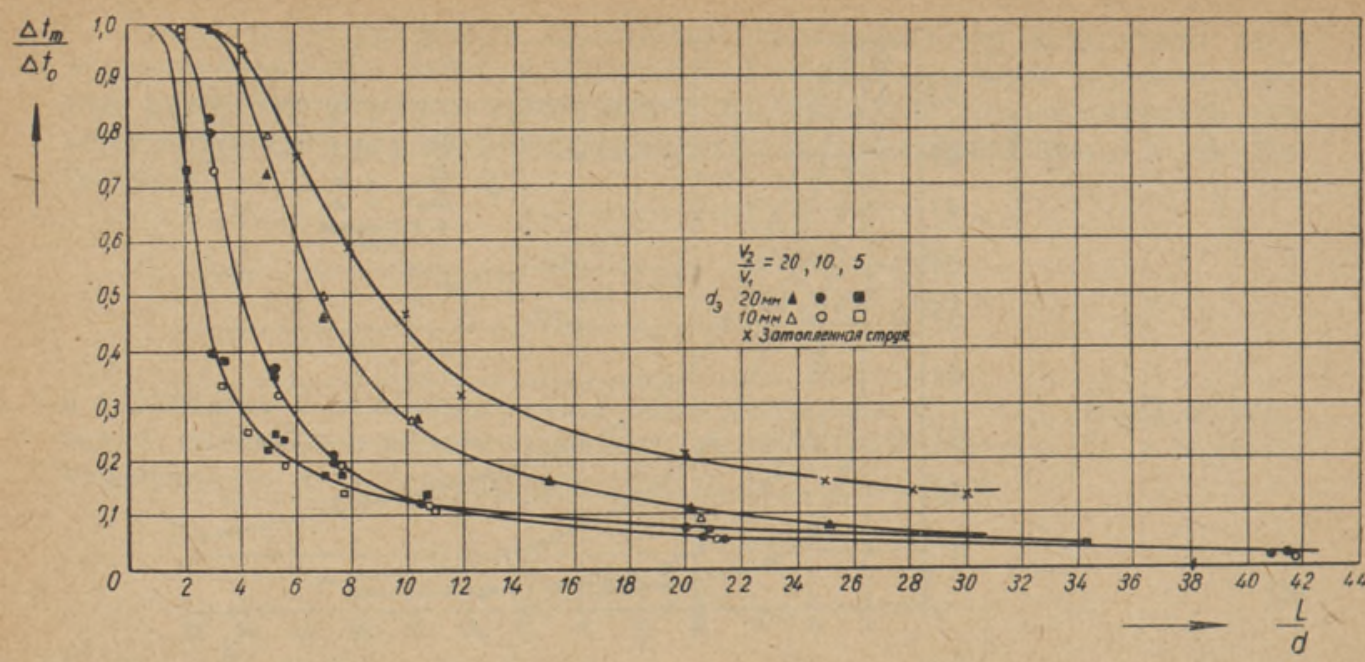

Фиг. 6. Изменение относительной разности температур вдоль оси круглой струи во внешнем потоке при $a=90^{\circ}$ и $\frac{T_{2}}{T_{1}}=2$.

Независимость изменения относительных разностей температур $\frac{\Delta t}{\Delta t_{0}}$ от абсолютного диаметра можно видеть на фиг. 6.

На фиг. $7, a ; 7,6$ и 8 сделана такая же обработка опытных данных в отношении поперечных прямоугольных струй. Под поперечными и продольными прямоугольными струями понимаются такие струи, у которых бо́льшая сторона устья (при соотношении 1:5) ставится, соответственно, то поперек, то вдоль внешнего потока.

На представленных графиках можно заметить, что закономерности скоростей и температур вдоль осей, выраженные в относительных величинах, оказываются верными как для круглых, так и прямоугольных струй во внешнем поперечном потоке, независимо от величины площади сечения струй.

Так же доказана независимость от диаметра траекторий струй в относительных координатах, не только для круглых струй, но и для поперечных прямоугольных струй (фиг. 9). Для обобщения поперечных прямоугольных струй различных по площадям выходных сечений (с отношением сторон в устье $1: 5)$, использован эквивалентный диаметр $d_{9}$, введенный впервые в работе $\left(^{5}\right)$. На фиг. 9 , а представлены траектории изотермических и неизотермических поперечных прямоугольных струй диаметрами $d_{9}=10$ и 20 мм при соотношениях скоростей $\frac{v_{2}}{v_{1}}=5,10$ и 20 . Нет никаких оснований сомневаться в независимости от диаметра траекторий продольных прямоугольных струй, построенных в относительных координатах. Траектории струй, определенные по скоростным замерам и по фотографиям изотермических и неизотермических струй, сравниваются, соответственно, на фиг. 9,6 и $9,8$.

Как видно из приведенных графиков, оба метода определения траекторий струй дали совпадение результатов.

Отметим, что прямоугольные струи различных эквивалентных диаметров, аналогично круглым струям, имеют в подобных опытах одинаковые траектории при построении их в относительных координатах. Это означает, с одной стороны, что размеры траекторий струй прямо пропорциональны диаметрам струй в устье и, с другой стороны, что каждой 

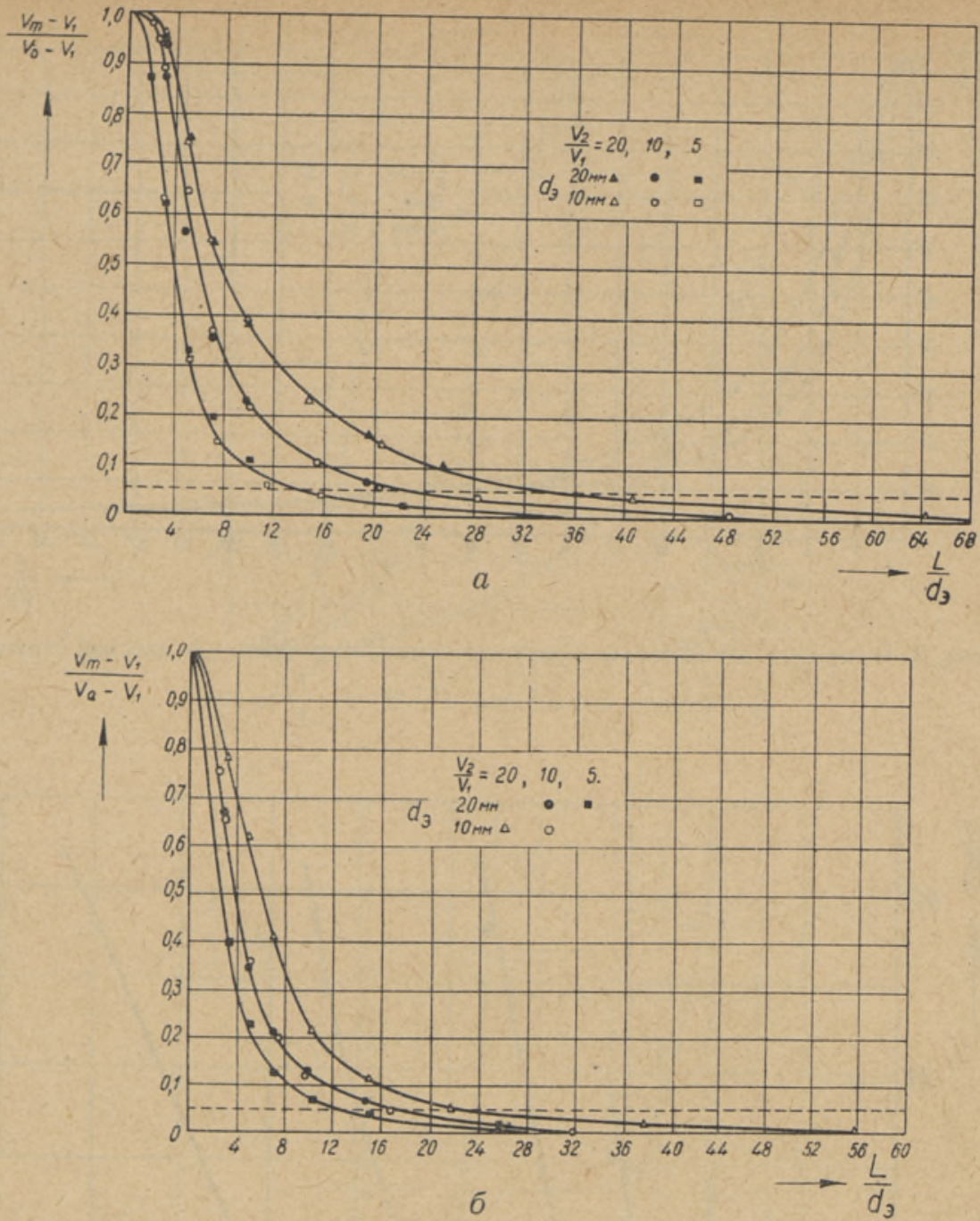

Фиг. 7. Изменение относительной разности скоростей вдоль оси плоской струи во внешнем потоке при $\alpha=90^{\circ}$;

$$
\text { a- при } \frac{T_{2}}{T_{1}}=1, \sigma-\text { при } \frac{T_{2}}{T_{1}}=2 .
$$

траектории, построенной в относительных координатах, соответствуют экспериментальные точки струй различных диаметров, т. е. что одна и та же траектория объединяет экспериментальные точки с различными значениями критерия $R e_{w}$ [употребляем индекс из работы $\left({ }^{9}\right)$ ].

Оба отмеченных выше обстоятельства, вытекающие из работы $\left({ }^{3}\right)$, т. е. независимость траекторий, построенных в относительных координатах, от диаметра и критерия $R e_{w}$, находятся в противоречии с окончательной расчетной формулой, приведенной в работе $\left({ }^{9}\right)$.

Опытами, проведенными при изменении значений критерия $R e_{w}$ в три раза, показано, что критерий Рейнольдса для струй, развивающихся во внешнем поперечном потоке, не имеет определяющего значения.

Представленные в данной статье графики и материалы, опубликованные ранее $\left({ }^{3}\right)$, убеждают нас в ошибочности расчетной формулы (3) в работе $\left({ }^{9}\right)$. 


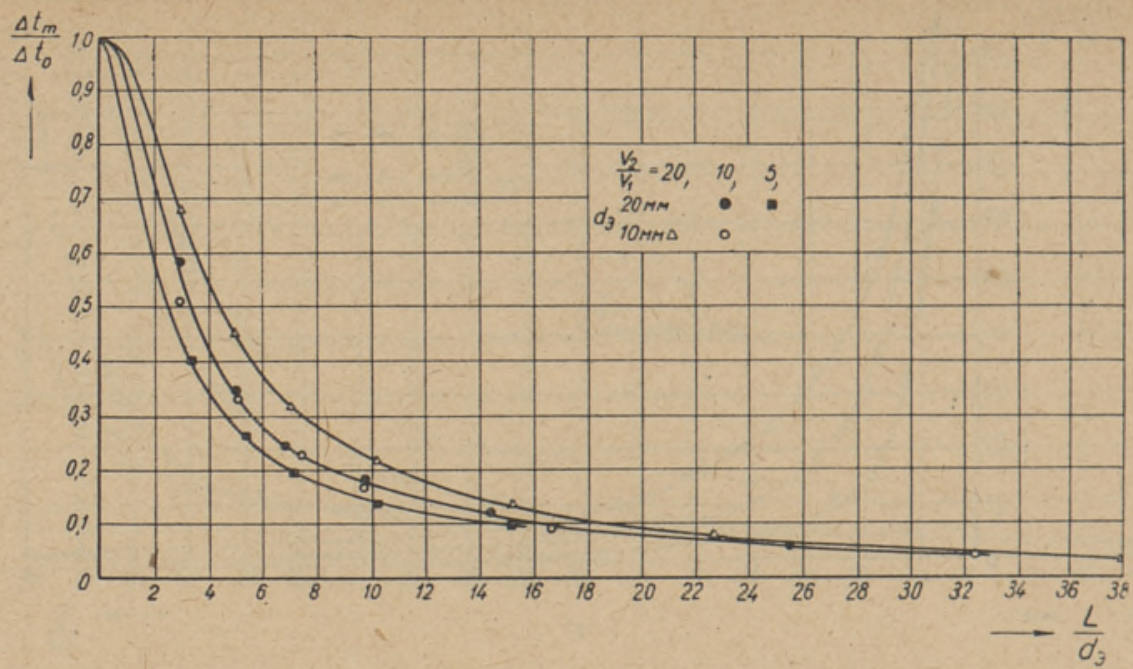

Фиг. 8. Изменение относительной разности температур вдоль оси плоской струи во внешнем потоке при $a=90^{\circ}$ и $\frac{T_{g}}{T_{1}}=2$.

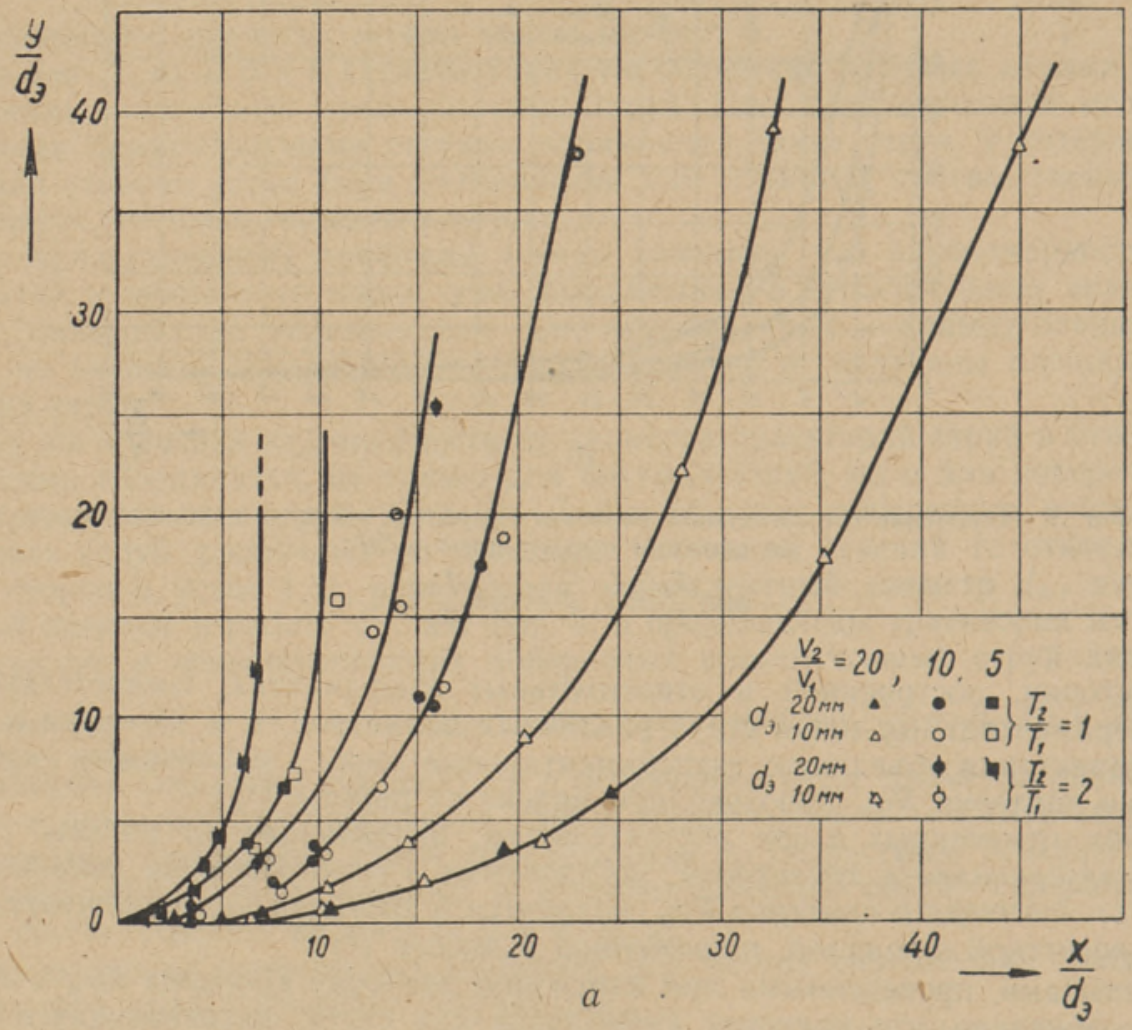

Фиг. 9. Траектории поперечных прямоугольных струй во внешнем потоке при $a=90^{\circ}$;

$$
a-\text { при } \frac{T_{2}}{T_{1}}=1 \text { и } 2 \text {, по замерам; }
$$



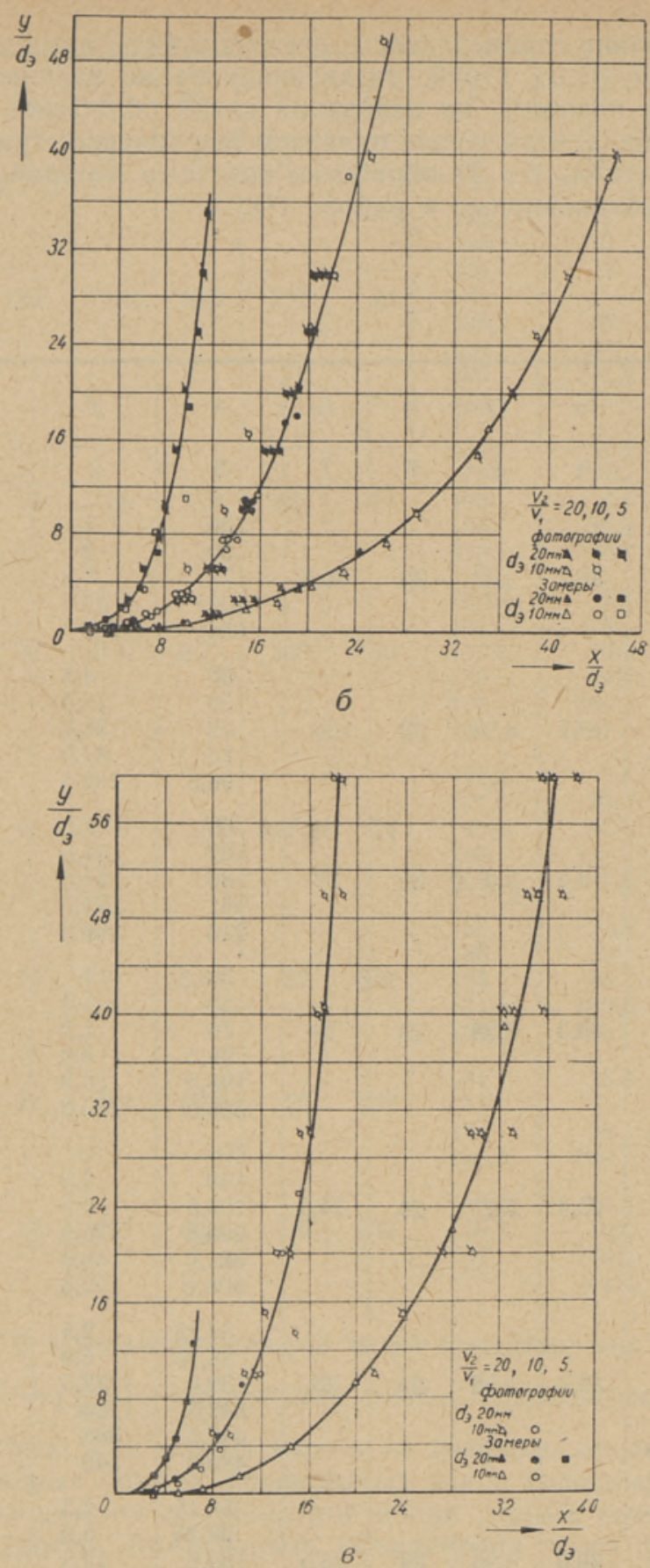

Фиг. 9. Траектории поперечных прямоугольных струй во внешнем потоке при $\alpha=90^{\circ}$;

б- при $\frac{T_{2}}{T_{1}}=1$, по замерам и фотографиям.

$8-$ при $\frac{T_{2}}{T_{1}}=2$, по замерам и фотографиям. 
В подтверждение справедливости рекомендуемой нами расчетной формулы (8) для круглых струй, развивающихся во внешнем поперечном потоке, остается показать, на основании какой обработки опытных данных она выведена. С этой целью приведем два графика (на фиг. 10 и 11) и две таблицы (табл. 1 и 2) обработки опытного материала с круглыми струями, не опубликованные в работе $\left({ }^{3}\right)$.

Таблица 1

\begin{tabular}{|c|c|c|c|c|c|c|c|c|c|c|}
\hline$\frac{v_{2}}{v_{1}}$ & $\alpha$ & $d_{9}$ & $v_{2}$ & $v_{1}$ & $t_{2}$ & $t_{1}$ & $x$ & $y$ & $\frac{x}{d_{9}}$ & $\frac{y}{d_{9}}$ \\
\hline 1 & 2 & 3 & 4 & 5 & 6 & 7 & 8 & 9 & 10 & 11 \\
\hline 10 & 90 & 10 & 36,7 & 3,67 & 32 & 30,5 & $\begin{array}{r}30 \\
50 \\
73 \\
100 \\
168\end{array}$ & $\begin{array}{c}1 \\
2 \\
7,5 \\
22 \\
105\end{array}$ & $\begin{array}{r}3,0 \\
5,0 \\
7,3 \\
10,0 \\
16,8\end{array}$ & $\begin{array}{c}0,1 \\
0,2 \\
0,75 \\
2,2 \\
10,5\end{array}$ \\
\hline 5 & 90 & 10 & 18,1 & 3,62 & 32 & 30 & $\begin{array}{l}30 \\
50 \\
62 \\
73 \\
96,5\end{array}$ & $\begin{array}{r}4,5 \\
18,0 \\
38,0 \\
67,0 \\
166,5\end{array}$ & $\begin{array}{l}3,0 \\
5,0 \\
6,2 \\
7,3 \\
9,65\end{array}$ & $\begin{array}{r}0,45 \\
1,80 \\
3,80 \\
6,70 \\
16,65\end{array}$ \\
\hline 5 & 90 & 20 . & 19,5 & 3,9 & 30 & 27 & $\begin{array}{r}63 \\
102 \\
130 \\
161 \\
216\end{array}$ & $\begin{array}{r}9,0 \\
31,5 \\
65,0 \\
123,0 \\
296,0\end{array}$ & $\begin{array}{c}3,15 \\
5,1 \\
6,5 \\
8,05 \\
10,8\end{array}$ & $\begin{array}{c}0,45 \\
1,575 \\
3,250 \\
6,150 \\
14,8\end{array}$ \\
\hline 20 & 90 & 10 & 73,3 & 3,58 & 29 & 29 & $\begin{array}{c}30 \\
50 \\
70 \\
99,5 \\
198,5 \\
368,0\end{array}$ & $\begin{array}{r}-1 \\
-1,5 \\
1,0 \\
3,0 \\
28,0 \\
160,0\end{array}$ & $\begin{array}{c}3 \\
5 \\
7 \\
9,95 \\
19,85 \\
36,8\end{array}$ & $\begin{array}{c}0 \\
0 \\
0,1 \\
0,3 \\
2,8 \\
16,0\end{array}$ \\
\hline 20 & 90 & 20 & 65,4 & 3,27 & 29 & 24,5 & $\begin{array}{l}100 \\
140 \\
190,5 \\
295,5 \\
391,0 \\
508,0\end{array}$ & $\begin{array}{r}0 \\
2,0 \\
6,0 \\
25,0 \\
50,0 \\
102,5\end{array}$ & $\begin{array}{c}5,0 \\
7,0 \\
9,52 \\
14,77 \\
19,55 \\
25,4\end{array}$ & $\begin{array}{l}0 \\
0,1 \\
0,3 \\
1,25 \\
2,5 \\
5,125\end{array}$ \\
\hline 10 & 90 & 20 & 39,6 & 3,96 & 29 & 25 & $\begin{array}{r}59,25 \\
98,25 \\
139,0 \\
348,5 \\
442,5 \\
489,0\end{array}$ & $\begin{array}{r}2,5 \\
5,0 \\
12,5 \\
186 \\
368 \\
540\end{array}$ & $\begin{array}{c}2,96 \\
4,912 \\
6,95 \\
17,42 \\
22,12 \\
24,45\end{array}$ & $\begin{array}{c}0,125 \\
0,25 \\
0,625 \\
9,3 \\
18,4 \\
27,0\end{array}$ \\
\hline 10 & 90 & 20 & 39,6 & 3,96 & 29 & 23,5 & $\begin{array}{c}59,25 \\
98,25 \\
139,0 \\
199,5 \\
348,5 \\
437,5\end{array}$ & $\begin{array}{r}2,5 \\
5,0 \\
12,5 \\
37,5 \\
186 \\
370\end{array}$ & $\begin{array}{c}2,962 \\
4,912 \\
6,95 \\
9,975 \\
17,42 \\
21,9\end{array}$ & $\begin{array}{c}0,125 \\
0,25 \\
0,625 \\
1,875 \\
9,3 \\
18,5\end{array}$ \\
\hline
\end{tabular}




\begin{tabular}{|c|c|c|c|c|c|c|c|c|c|c|}
\hline$\frac{v_{2}}{v_{1}}$ & $\alpha$ & $d_{9}$ & $v_{2}$ & $v_{1}$ & $t_{2}$ & $t_{1}$ & $x$ & $y$ & $\frac{x}{d_{9}}$ & $\frac{y}{d_{3}}$ \\
\hline 1 & 2 & 3 & 4 & 5 & 6 & 7 & 8 & 9 & 10 & 11 \\
\hline 20 & 90 & 20 & 70,45 & 3,68 & 332 & 28 & $\begin{array}{l}39 \\
60 \\
100 \\
139 \\
199,5 \\
294 \\
380 \\
456\end{array}$ & $\begin{array}{c}0 \\
0 \\
3 \\
5,5 \\
16 \\
54 \\
107,5 \\
170\end{array}$ & $\begin{array}{c}1,95 \\
3,0 \\
5,0 \\
6,95 \\
10 \\
14,7 \\
19,0 \\
22,8\end{array}$ & $\begin{array}{l}0 \\
0 \\
0,15 \\
0,277 \\
0,8 \\
2,70 \\
5,37 \\
8,5\end{array}$ \\
\hline 20 & 90 & 10 & 75,6 & 3,78 & 327 & 27 & $\begin{array}{c}50 \\
70,5 \\
100 \\
193 \\
318\end{array}$ & $\begin{array}{r}1,0 \\
2,0 \\
6,5 \\
56,5 \\
233\end{array}$ & $\begin{array}{c}5,0 \\
7,05 \\
10,0 \\
19,3 \\
31,8\end{array}$ & $\begin{array}{c}0,1 \\
0,2 \\
0,65 \\
5,65 \\
23,3\end{array}$ \\
\hline 10 & 90 & 20 & 37,0 & 3,7 & 332 & 29 & $\begin{array}{l}60,3 \\
101 \\
139,8 \\
188 \\
276 \\
344\end{array}$ & $\begin{array}{c}5,3 \\
16 \\
39,0 \\
89,0 \\
280 \\
\in 81\end{array}$ & $\begin{array}{c}3,015 \\
5,05 \\
6,99 \\
9,4 \\
13,8 \\
17,2\end{array}$ & $\begin{array}{l}0,265 \\
0,8 \\
1,95 \\
4,45 \\
14,0 \\
34,05\end{array}$ \\
\hline 10,2 & 90 & 10 & 38,7 & 3,81 & 348,5 & 24 & $\begin{array}{c}52,5 \\
71,0 \\
95,6 \\
148 \\
203\end{array}$ & $\begin{array}{r}8,0 \\
20,0 \\
42,0 \\
134 \\
334,5\end{array}$ & $\begin{array}{c}5,25 \\
7,10 \\
9,56 \\
14,8 \\
20,3\end{array}$ & $\begin{array}{c}0,8 \\
2,0 \\
4,2 \\
13,4 \\
33,45\end{array}$ \\
\hline 5 & 90 & 20 & 19 & 3,8 & 29 & 331 & $\begin{array}{c}60 \\
86 \\
105 \\
121,5 \\
166,5\end{array}$ & $\begin{array}{c}24,5 \\
59 \\
98 \\
160,5 \\
358\end{array}$ & $\begin{array}{l}3,0 \\
4,3 \\
5,25 \\
6,07 \\
8,32\end{array}$ & $\begin{array}{c}1,22 \\
2,95 \\
4,9 \\
8,02 \\
17,9\end{array}$ \\
\hline 5 & 90 & 20 & 18,4 & 3,68 & 28 & 332 & $\begin{array}{c}61 \\
82 \\
105 \\
123,5\end{array}$ & $\begin{array}{c}23,5 \\
51 \\
98 \\
160\end{array}$ & $\begin{array}{l}3,05 \\
4,1 \\
5,25 \\
6,17\end{array}$ & $\begin{array}{l}1,17 \\
2,55 \\
4,9 \\
8,0\end{array}$ \\
\hline 5 & 90 & 10 & 18,4 & 3,68 & 26 & 332 & $\begin{array}{l}48,5 \\
38,5 \\
61 \\
77\end{array}$ & $\begin{array}{l}25,5 \\
16,0 \\
44,5 \\
74,5\end{array}$ & $\begin{array}{l}4,85 \\
3,85 \\
6,1 \\
7,7\end{array}$ & $\begin{array}{l}2,55 \\
1,60 \\
4,45 \\
7,45\end{array}$ \\
\hline
\end{tabular}

На фиг. 10 в логарифмической сетке представлены траектории круглых струй $\frac{a y}{d}=f\left(\frac{a x}{d}\right)$, образующие девять параллельных прямых. Большинство прямых, как можно видеть из графика, проведены по точкам, взятым из разных опытов, проведенных кақ с холодными, так и с горячими струями различных диаметров и при разных соотношениях скоростей и температур. Возможность объединения точек разных опытов в единую прямую дается применением предложенного нами параметра $\frac{\delta_{1} v_{1}^{2}}{\varrho_{2} v_{2}^{2}}$. Достаточно было в опытах выдерживать численное значение этого параметра, чтобы опытные точки, соответствующие траекториям холодных и горячих струй, попадали на одну и ту же прямую.

На фиг. 10 можно также заметить, что траектории струй с различной начальной турбулентностью введением коэффициента структуры струй $a$ 


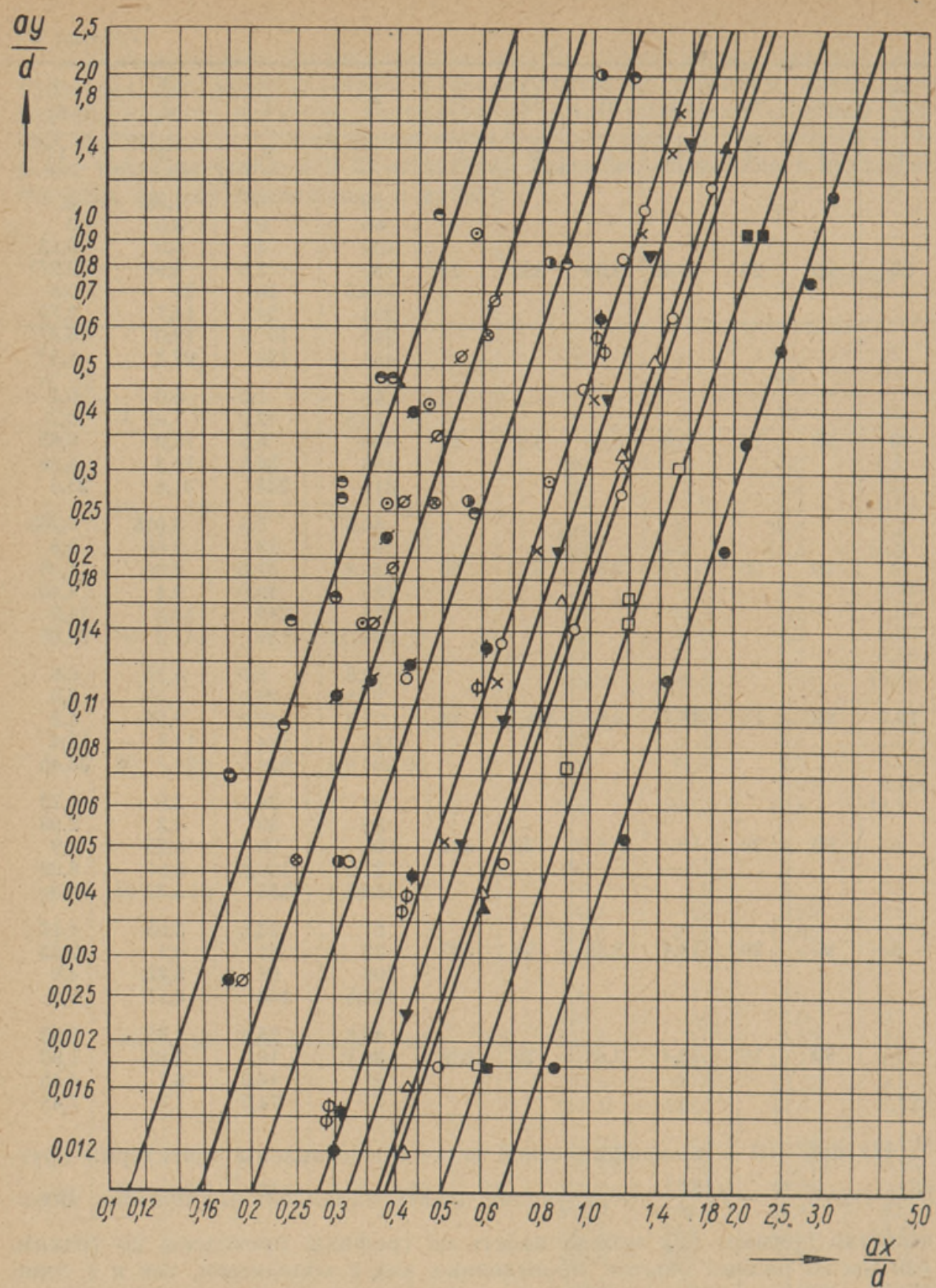

Фиг. 10. Траектории круглых струй во внешнем поперечном потоке.

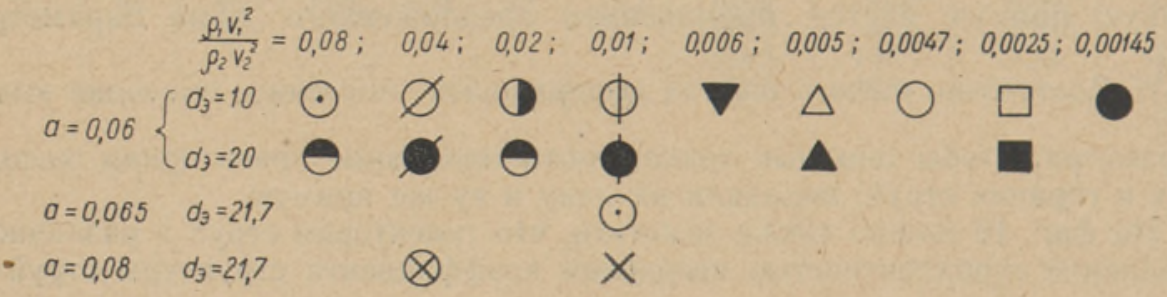


(при прочих равных условиях) обобщаются в единую траекторию. Расхождение между траекториями характеризуется тогда лишь различием значений определяющего параметра $\frac{\varrho_{1} v_{1}^{2}}{\varrho_{2} v_{2}^{2}}$.

Для нахождения вида зависимости относительной дальнобойности струй $D_{1}$ от этого параметра и получения расчетной формулы на фиг. 11 в логарифмической сетке построен график $D_{1}=f\left(\frac{\varrho_{2} v_{2}^{2}}{\varrho_{1} v_{1}^{2}}\right)$ (для удобства установления расчетной формулы определяем зависимость от величины, обратной предложенному параметру).

На фиг. 11 нанесены точки опытов не только с круглыми, но и с продольными и поперечными прямоугольными струями. Относительные

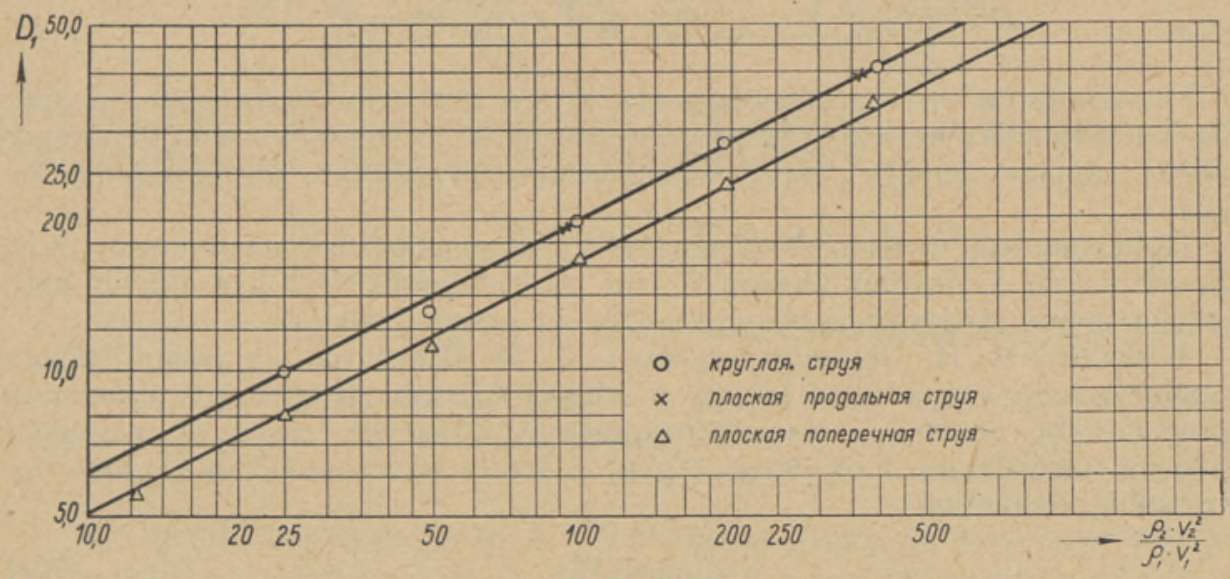

Фиг. 11. Дальнобойности струй во внешнем поперечном потоке при $a=90^{\circ}$.

дальнобойности прямоугольных струй выражены в эквивалентных диаметрах $d_{9}$. На графике можно видеть, что дальнобойности круглых и продольных прямоугольных струй между собой равны. Опытные точки этих струй укладываются на верхнюю прямую, а опытные точки поперечных прямоугольных струй образуют нижнюю прямую. Это указывает на то, что дальнобойность струи $D_{1}$ для каждой прямой можно выразить степенной зависимостью вида:

$$
D_{1}=k_{1}\left(\frac{\varrho_{2} v_{2}^{2}}{\varrho_{1} v_{1}^{2}}\right)^{q}
$$

Обработкой верхней прямой линии на фиг. 11 получим $k_{1}=2$ и $q=0,5$. Расчетная формула дальнобойности круглых и продольных прямоугольных струй, развивающихся во внешнем поперечном потоке, прнмет вид приведенной выше формулы (6).

Дальнобойность поперечных прямоугольных струй тех же эквивалентных диаметров примерно на 20\% меньше дальнобойности круглых или продольных прямоугольных струй.

Прежде чем перейти к методике расчета газовой горелки, коснемся влияния на траекторию струи разности в удельных весах жидкостей, составляющих струю и поперечный поток. В работе Института теплоэнергетики АН УССР формула (3) для расчета дальнобойности получена в результате опытов с, одинаковыми жидкостями, имевшими равные темпе- 
ратуры, т. е. равные плотности. В работе указывается на возможность пренебречь разницей в значениях плотностей струи й поперечного потока, если она не очень велика: так, например, для указанного в работе И. И. Чернобыльского и Г. М. Щеголева случая удельный вес воздуха $\gamma_{\mathrm{B}}=1,293 \mathrm{\kappa г} / \mathrm{Hм}^{3}$, а удельный вес газа $\gamma_{\mathrm{r}}=0,4 \mathrm{Kr} / \mathrm{HM}^{3}$.

Опытами $\left({ }^{3}\right)$, проведенными с жидкостями разной плотности, это предположение не подтвердилось. На основании формулы (6), приведенной в данной работе для расчета дальнобойности круглых струй, можно определить, какова будет ошибка расчета для условий примера, приведенного в работе $\left({ }^{9}\right)$.

Формула дальнобойности струй (6) при замене $\varrho$ на $\gamma$ и при подстановке численных значений, отвечающих рассматриваемому случаю, примет .вид:

$$
D_{1}=k_{1} \frac{v_{2}}{v_{1}} \sqrt{\frac{\gamma_{\mathrm{r}}}{\gamma_{\mathrm{B}}}}=k_{1} \frac{v_{2}}{v_{1}} \sqrt{\frac{0,4}{1,293}}=k_{1} \frac{v_{2}}{v_{1}} \cdot 0,55
$$

Оказывается, что дальнобойность струи с учетом указанного различия в плотностях взаимодействующих потоков составляет лишь половину $(55 \%)$ дальнобойности струи, рассчитываемой без учета различия в плотностях.

Приведенный пример показывает, что пренебрегать различием плотностей струи и потока нельзя и что дальнобойность струи пропорциональна корню квадратному из отношения плотностей.

В работе И. И. Чернобыльского и Г. М. Щеголева из рассмотрения конфигурации струи (вид сверху и сбоку) сделан интересный, имеющий практическое значение, вывод: отношение диаметра струи $D$, измеренного на расстоянии $h$ от устья струи, к этому расстоянию оказалось постоянной величиной:

$$
\frac{D}{h} \approx 0,75
$$

Диаметры струи, измеренные в горизонтальной и вертикальной проекциях, оказались равными между собой. Это дает возможность судить о размерах поперечного сечения струи, которое необходимо знать при выборе диаметров отверстий (сопел) для выхода газа и расстояний между отверстиями.

Обработка фотографий струй, заснятых при экспериментальном исследовании $\left({ }^{3}\right)$, подтвердила вышеуказанное соотношение (9), причем расхождения в отдельных опытах находились в пределах от 0,7 до 0,75 В целях обеспечения более надежных условий перемешивания предпочтительно взять верхний предел отношения $\frac{D}{h} \approx 0,75$, рекомендованный в работе $\left({ }^{9}\right)$.

\section{Методика расчета смешения струи с поперечным потоком}

В работе $\left({ }^{9}\right)$ отмечается, что при равных высотах струй смешение будет тем лучше, чем меньше диаметр струи, и в связи с этим рекомендуется при расчете выбирать минимальные размеры отверстий. Далее, исходя из установленных выше закономерностей, указывается, что равномерное перемешивание газа с воздушным потоком, как правило, следует осуществлять созданием двух или даже большего числа струй различной высоты. Только при таких условиях можно равномерно заполнить воздушный поток струями газа, с тем чтобы самые низкие струи вытекали из 
отверстий малого диаметра; а если такой диаметр будет установлен, тогда уже легко будет определить диаметр отверстий, предназначенных для получения более дальнобойных струй.

Все высказанные соображения, направленные к лучшей организации перемешивания струй, согласуются с нашими выводами из работы $\left({ }^{3}\right)$, однако расчетные рекомендации, сделанные в работе $\left({ }^{9}\right)$, как будет показано ниже, требуют корректировки.

Воспользуемся обозначениями, принятыми в работе $\left({ }^{9}\right)$. Минимально допустимый, с точки зрения засорения, диаметр отверстий обозначится $d_{\min }$, высота вытекающей струи - $h_{\min }$, а диаметр и высота большой струи $-d_{\max }$ и $h_{\max }$. При одинаковой скорости истечения $u$ в один и тот же поперечный поток, имеющий скорость $w$, в работе $\left({ }^{9}\right)$ рекомендуется формула для расчета соотношения диаметров струй в виде:

$$
\frac{d_{\max }}{d_{\min }}=\left(\frac{h_{\max }}{h_{\min }}\right)^{1,48} ; \quad d_{\max }=d_{\min }\left(\frac{h_{\max }}{h_{\min }}\right)^{1,48} .
$$

Приведем из нашего исследования $\left({ }^{3}\right)$ формулу для определения диаметра. Напишем уравнение (8) для двух струй в виде:

$$
\frac{h_{\min }}{d_{\min }}=2,2 \frac{u}{w} \sqrt{\frac{\varrho_{2}}{\varrho_{1}}} \text { и } \frac{h_{\max }}{d_{\max }}=2,2 \frac{u}{w} \sqrt{\frac{\varrho_{2}}{\varrho_{1}}} .
$$
ний:

Разделив одно на другое, получим после элементарных преобразова-

$$
d_{\max }=d_{\min } \frac{h_{\max }}{h_{\min }} .
$$

Из сравнення формул 10 и 11 отчетливо видно их расхождение. Диаметр сечения малых струй на расстоянии $h_{\min }$. от плоскости устья $D_{\min }=$ $=0,75 h_{\min }$. Диаметр сечения больших струй на расстоянии $h$ от плоскости устья $D_{\max }=0,75 h_{\max }$.

Кроме расчета диаметров отверстий, необходимо еще определить скорость истечения струи $u$ во внешний поперечный поток. Она определится из уравнения (8) данной работы:

$$
u=\frac{h w}{d \cdot 2,2} \sqrt{\frac{\varrho_{w}}{\varrho_{u}}} .
$$
лой:

Эта же скорость истечения согласно работе $\left({ }^{9}\right)$ определится форму-

$$
u=\frac{h_{\min }^{0,77} \cdot v_{u} \cdot w^{1,25}}{\mathrm{C}^{0,77} d_{\min }^{0,52} \cdot v_{w}^{1,25}} .
$$

Для выяснения величины расхождения сделаем расчеты и сопоставление результатов смешения по рекомендациям работ $\left({ }^{9}\right)$ и $\left({ }^{3}\right)$, применительно к условиям примера, указанного в работе И. И. Чернобыльского и Г. М. Щеголева.

Расчет будем производить для комбинированной пыле-газовой горелки, представляющей собой видонзмененную конструкцию пылевой горелки типа ОРГРӘС, приспособленную для сжигания пыли и газа.

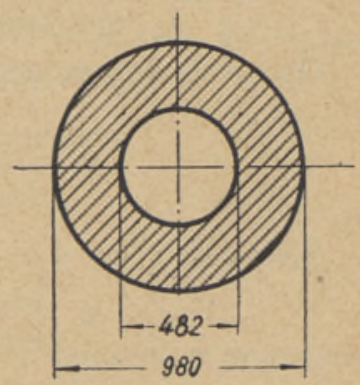

Фиг. 12. Поперечное сеченке воздушного канала горелкн. 
Исходные данные для расчета

Производительность горелки - 2500 нм $^{3} /$ час.

Размеры канала, по которому протекает воздух, даны на фиг. 12 (канал заштрихован).

Количество воздуха - $26000 \mathrm{Hм}^{3} /$ час.

Кинематическая вязкость газа (дашавского) при $p=1$ ата и $t=10^{\circ} \mathrm{C}$ $v_{u}=14,27 \cdot 10^{-6} \mathrm{M}^{2} /$ сек.

Удельный вес газа $\gamma_{\mathrm{r}}=0,75 \mathrm{\kappa r} / \mathrm{m}^{3}$.

Кинематическая вязкость воздуха при $p=1$ ата и $t=270^{\circ} \mathrm{C}: v_{w}=$ $=45.7 \cdot 10^{-6} \mathrm{M}^{2} /$ сек. Удельный вес воздуха $\gamma_{\mathrm{B}}=1,293 \cdot \frac{273}{273+270}=0,65 \mathrm{\kappa r} / \mathrm{m}^{3}$.

$\mathrm{P}$ a с ч е $\mathrm{T}$

1. Количество воздуха $V_{0}=26000 \mathrm{Hм}^{3} /$ час

или $V=\frac{V_{0} T}{T_{0}}=\frac{26000 \cdot 543}{273}=51800 \mathrm{~m}^{3} /$ час.

2. Скорость воздуха в канале: а) поступательная

$$
w_{0}=\frac{V}{\frac{\pi\left(\mathrm{D}_{\text {нар }}-\mathrm{D}_{\text {вн }}\right) 3600}{4}}=\frac{51800}{0,785 \cdot\left(0,98^{2}-0,482^{2}\right) \cdot 3600}=25,2 \mathrm{M} / \text { сек; }
$$

б) действительная скорость с учетом движения воздуха по спирали с углом подъема $\beta=30^{\circ}$

$$
w=\frac{w_{0}}{\operatorname{Sin} 30^{0}}=\frac{25,2}{0,5}=50,4 \mathrm{~m} / \text { сек. }
$$

3. Выбор расположения осей струй сделан в соответствии с работой $\left({ }^{9}\right)$ согласно фиг. $13, a$.

4. Диаметр отверстий для образования больших струй определится по уравнению $(10)$, принимая минимальный размер $d_{\min }=2$ мм:

$$
d_{\max }=d_{\min }\left(\frac{h_{\max }}{h_{\min }}\right)^{1,48}=2\left(\frac{85}{42,5}\right)^{1,48} \approx 5,5 \mathrm{мм} .
$$

5. Необходимая скорость истечения, подсчитанная по уравнению (13), оказалась равной 170 м/сек.

Распределение струй, по расчету И. И. Чернобыльского и Г. М. Щеголева, получилось равномерным по сечению горелки, как показано на фиг. $13, a$.

Сделаем проверку расчета по рекомендациям работы $\left({ }^{3}\right)$, принимая за основу те же диаметры отверстий и те же скорости (т. е. $d_{\min }=2$ мм; $d_{\max }=5,5$ мм; $u=170 \mathrm{м} /$ сек; $w=50,4 \mathrm{м} /$ сек).

Дальнобойность струй определим по формуле (8):

$$
\frac{h}{d}=2,2 \frac{u}{w} \sqrt{\frac{\varrho_{u}}{\varrho_{w}}} .
$$

Заменяя $\varrho$ на $\gamma$ и подставляя численные значения, получим:

$$
\frac{h}{d}=2,2 \frac{u}{w} \sqrt{\frac{\gamma_{u}}{\gamma_{w}}}=2,2 \frac{170}{50,4} \sqrt{\frac{0,75}{0,65} \approx 8,0^{*} .}
$$

* В действительности дальнобойность струи газа будет еще меньше, так как скорость воздуха в канале вследствие подвода газа возрастет с $50,4 \mathrm{~m} /$ сек до $53 \mathrm{~m} / \mathrm{ceк}$. 
Для струй меньшего диаметра, вытекающих из отверстий $d_{\min }=2$ мм,

$$
h_{\min }=8,0 \cdot d_{\min }=8,0 \cdot 2=16,0 \mathrm{Mм} .
$$
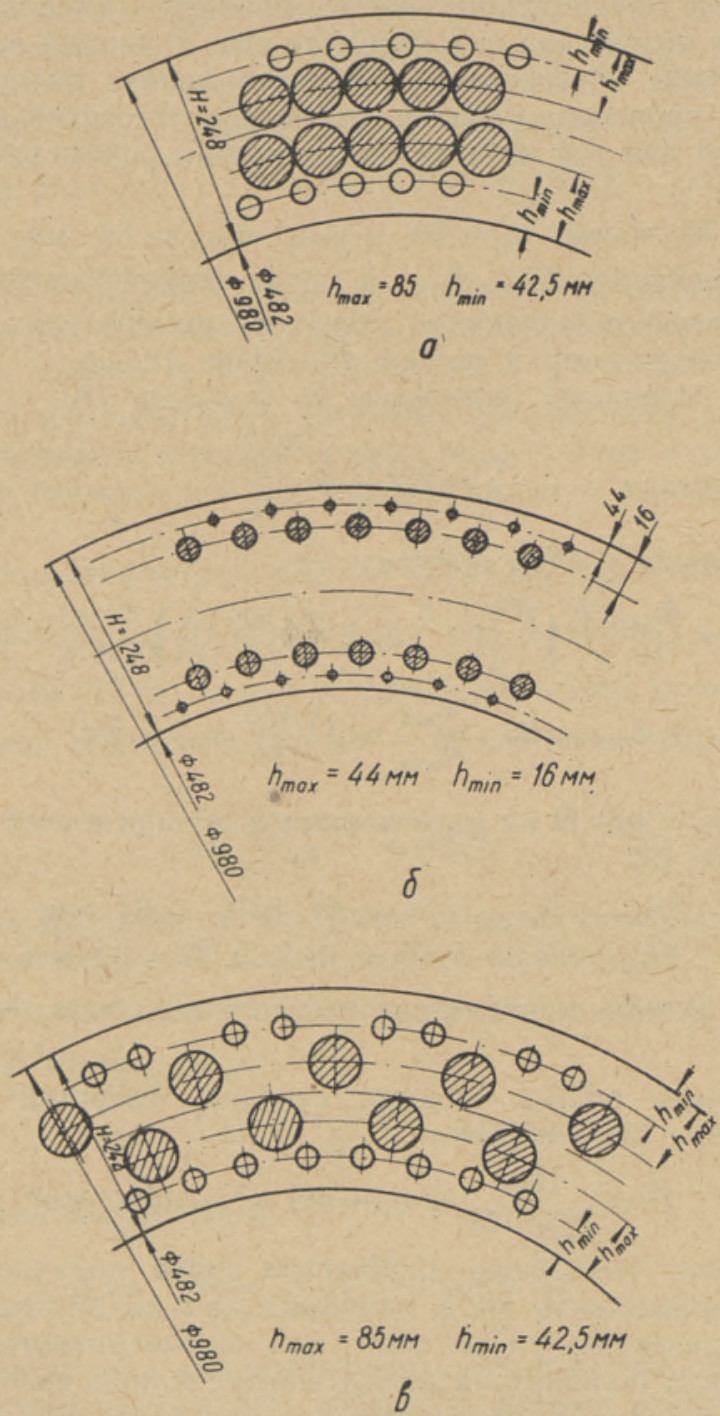

Фиг. 13. Распределение газовых струй в воздушном канале:

$a$ - по расчету И. И. Чернобыльского и Г. М. Щеголева,

б - результаты проверки расчета по методу автора,

6 - один из возможных вариантов распределения струй согласно расчету по методу автора.

Для струй большего диаметра, $d_{\max }=5,5$ мм,

$$
h_{\max }=8,0 \cdot d_{\max }=8,0 \cdot 5,5=44 \mathrm{mM}
$$

Диаметры струй $D$ на расстоянии $h$ от плоскости выхода определяем по формуле (9):

$$
\begin{aligned}
& D_{\min }=h_{\min } \cdot 0,75=16,0 \cdot 0,75=12 \text { мм; } \\
& D_{\max }=h_{\max } \cdot 0,75=44 \cdot 0,75=33 \mathrm{мм}
\end{aligned}
$$


Полученное в результате наших расчетов распределение струй показано на фиг. 13,6 . Как видно из фиг. 13,6 , выбранные в работе $\left({ }^{9}\right)$ диаметры отверстий и скорости струй при заданной скорости потока приведут к неудачной организации перемешивания - вдоль стенок канала будет двигаться поток газа, а в середине его - чистый воздух.

Для того чтобы обеспечить более равномерное распределение струй газа в воздухе, произведем расчет диаметров отверстий и скорости истечения струй газа для той же горелки по нашим рекомендациям.

$\mathrm{P}$ а с ч е т

Дано $u=170 \mathrm{~m} /$ сек; $w=53 \mathrm{м} /$ сек; $h_{\max }=85 \mathrm{мм} ; h_{\min }=42,5 \mathrm{мм}$. Необходимо определить $d_{\max }, d_{\min }$, а также количество отверстий на внутренней и наружной поверхностях горелки применительно к распределению струй, приведенному в работе $\left({ }^{9}\right)$ (фиг. $\left.13, a\right)$.

1. Диаметр отверстий определим по формуле (8):

$$
\frac{h}{d}=2,2 \frac{u}{w} \sqrt{\frac{\varrho_{u}}{\varrho_{w}}}
$$

из которой, заменяя $\varrho$ на $\gamma$, получим:

$$
\begin{gathered}
d_{\max }=\frac{h_{\max } \cdot w}{2,2 \cdot u} \sqrt{\frac{\gamma_{w}}{\gamma_{u}}} ; \quad d_{\max }=\frac{85 \cdot 53}{2,2 \cdot 170} \sqrt{\frac{0,65}{0,75} \cong 11 \mathrm{MM},} \\
d_{\min }=d_{\max } \frac{h_{\min }}{h_{\max }}=11 \frac{42,5}{85}=5,5 \mathrm{Mм} .
\end{gathered}
$$

2. Диаметры струй $D$ на расстояниях $h$ от плоскостей выхода определяем по формуле (9)

$$
\begin{aligned}
& D_{\max }=h_{\max } \cdot 0,75=85 \cdot 0,75 \approx 64 \mathrm{мм}, \\
& D_{\min }=h_{\min } \cdot 0,75=42,5 \cdot 0,75 \approx 32 \mathrm{мм} .
\end{aligned}
$$

Расстояния между центрами струй должны быть больше значений $D_{\max }$ и $D_{\min }$.

3. Необходимая общая площадь сечений отверстий при производительности горелки $2500 \mathrm{~m}^{3} /$ час

$$
F=\frac{2500}{3600 \cdot 170}=0,00408 \mathrm{~m}^{2}=4080 \mathrm{mм}^{2} .
$$

4. Ввиду того, что общее количество струй получается небольшое, имеет смысл расположить их в один ряд как по внутренней, так и по наружной поверхностям. При этом для симметричного расположения малых струй среди больших задаемся соотношением их чисел $1: 2$. Если число струй большего диаметра будет в два раза меньше числа струй малого диаметра, то при выбранных диаметрах (11 и 5,5 мм) отношение между площадями отверстий будет, наоборот, $2: 1$, т. е. две трети площади придется на отверстия большого диаметра, а одна треть - на отверстия малого диаметра.

5. Количество струй определится

a) диаметром 11 мм -

$$
\begin{aligned}
\frac{2}{3} F & =\frac{2}{3} 4080=2720 \mathrm{мм}^{2} \\
n & =\frac{2720}{\frac{\pi d^{2}{ }_{\max }}{4}}=\frac{2720}{\frac{3,14 \cdot 11^{2}}{4}}=28,6
\end{aligned}
$$

прннимаем $n_{1}=29$ струй; 
б) диаметром 5,5 мм -

$$
\begin{gathered}
F=4080-2720=1360 \mathrm{M}^{2} \\
n=\frac{1360}{\frac{\pi d^{2}{ }_{\text {min }}}{4}}=\frac{1360}{\frac{3,14 \cdot 5,5^{2}}{4}}=57,5
\end{gathered}
$$

принимаем $n_{2}=58$ струй; общее число струй $29+58=87 ;$ общая площадь всех струй $F=\frac{\pi}{4}\left(n_{1} \cdot 11^{2}+n_{2} \cdot 5,5^{2}\right)=0,785\left(29 \cdot 11^{2}+58 \cdot 5,5^{2}\right)=$ $=4130 \mathrm{~m} \mathrm{M}^{2}$.

Расхождение получившейся площади с расчетной составляет 4130 - $4080=50$ мм² $^{2}$ его можно устранить, исключив два отверстия диаметром 5,5 мм (по одному в каждом ряду).

6. Число струй в одном ряду (условно, для расчета совмещаем на одну окружность большие и малые струи) определится исходя из равенства шагов между струями на своих окружностях в кольцевом сечении горелки:

а) по окружности диаметром $482 \mathrm{mм}+(2 \cdot 85) \mathrm{мm}=652$ мм;

задаемся шагом $t \simeq 53$ мм, тогда $n=\frac{3,14 \cdot 652}{53}=38,7$;

принимаем $n=39$ струй, из них у тринадцати струй $d=11$ мм;

б) по окружности диаметром 980 мм - (2 85) мм $=810$ мм, при шаге $t \cong 53 \mathrm{MM}$

$$
n=\frac{3,14 \cdot 810}{53} \approx 48,0
$$

Принимаем $n=48$ струй, из них у шестнадцати струй $d=11$ мм. Это соответствует принятому нами общему числу струй $87(39+48=87)$.

7. Определяем шаг между отверстиями в одном ряду

а) по наружной поверхности:

$$
t_{1}=\frac{\pi D_{1}}{n}=\frac{3,14 \cdot 980}{48} \approx 64,2 \mathrm{MM},
$$

б) по внутренней поверхности:

$$
t_{2}=\frac{\pi D_{2}}{n}=\frac{3,14 \cdot 482}{39} \simeq 38,8 \text { мM. }
$$

Из расчета следует, что для обеспечения в кольцевом сечении равных шагов между струями необходимо создавать разные расстояния между отверстиями на внутренней и внешней поверхностях горелки.

Распределение струй газа в кольцевом сечении показано на фиг. $13, \boldsymbol{8}^{*}$.

Расстояние ряда отверстий от края газовой горелки, обращенного в топку, желательно, исходя из требований перемешивания, делать наибольшим. На основании графиков перемешивания струй из работы при данном режиме можно рекомендовать это расстояние $\approx 300$ мм.

Необходимо, однако, иметь в виду, что как в работе И. И. Чернобыльского и Г. М. Щеголева, так и в данной работе не внесены в расчет поправки на увеличение скорости воздуха в кольцевом сечении горелки за

* Приведенный пример распределения струй не является оптимальным, возможны и другие расчетные решения в части распределения струй. Автором расчет приведен лишь для пояснения того, какие должны быть выбраны диаметры отверстий, если следовать схеме расположения струй, предложенной в работе $\left({ }^{9}\right)$. 
счет загромождения сечения струями газа. В обеих работах также имеются допущения, заключающиеся в том, что результаты опытов со струей в плоском потске применяются к совокупности струй во вращающемся потоке.

Все отмеченные обстоятельства влияют в одну сторону, указывая, что фактическая дальнобойность струй может быть только меньше, но никак не больше дальнобойности, полученной по расчету.

По мере накопления экспериментального материала о закономерностях развития струи во вращающемся потоке методика расчета газовых горелок будет уточняться.,

В заключение отметим, что в горелках необходимо стремиться к более полному перемешиванию не только для уменьшения химического недожога, что, конечно, очень существенно, но и для борьбы с пульсациями в топке. Неравномерность перемешивания газа с воздухом создает в одних местах очаги горения, а в других местах, с недостатком воздуха, газ разлагается на сажу, водород и окись углерода. Эти явления приводят в худших случаях, с одной стороны, к густому сажистому дыму и, с другой стороны, благодаря неустойчивости воспламенения и непрерывно изменяющемуся фронту горения - к хлопкам и пульсациям в топке котлов; иногда даже части котла и котельной начинают вибрировать в резонанс пульсациям в топке. На явления вибрации отопительных ланкаширских котлов, работающих на природном газе, установленных на овощной фабрике, указывается в статье А. К. Лыского $\left({ }^{8}\right)$ : «На многих отопительных и промышленных котлах имеют место пульсации в топке, переходящие в часто повторяемые хлопки, которые периодически становятся настолько сильными, что перекрывают все остальные шумы и звуки в котельной». Полностью избавиться от шума и пульсации в топке удалось, как об этом сообщает А. К. Лыский, заменив горелки Энергопроекта типа ӘПГ турбулентными горелками, дающими лучшее перемешивание газа с воздухом.

Сделанные в данной статье рекомендации могут быть использованы как при расчете новых горелок, так и при исправлении старых типов горелок, основанных на рассмотренных выше принципах перемешивания.

Ннститут энергетики

Академии наук Эстонской ССР

Поступила в редакцию 11 XI 1953

\section{ЛИТЕРАТУРА}

1. Г. Н. А бр а м в и ч, Турбулентные свободные струи жидкостей и газов, М.-Л, Госэнергоиздат, 1948

2. Н. Н. Доброхотов, K динамике диффузионных процессов, Изд. АН УССР, 1948.

3. Ю. В. Иванов, Уравнения траекторий струй острого дутья. «Котлотурбостроение», № 8, 1952.

4. М. А. Куз ь м ин, Основы теории печей, 1937.

5. Д. Н. Л яховски й и С. Н. Сыркин, Применение острого дутья, Информационное письмо ЦКТИ, № 14, 1944.

6. Д. Н. Л яховский, Аэродинамика струевых и факельных процессов, Сборник ЦКТИ жТеплопередача и аэродннамнка», кн. 12, вып. 3, 1949.

7. Д. Н. Л яховски й и С. Н. С ы кин, Аэродинамика факела, вытекающего в среду другой плотности, Журнал технической физики, №9, 1939.

8. А. К. Л ыс ки й, Борьба с пульсациями в топках котлов при сжигании газа, «За экономию топлива», № 4, 1952.

9. И. И. Чернобыльский и Г. $M$. Щеголев, Экспериментальное исследование процесса смешения струй в поперечном потоке, Труды Института теплоэнергетики АН УССР, № 7, 1952.

10. K. Rum m l, Der Einfluss des Mischvorganges auf die Verbrennung von Gas und Luft in Feuerungen, Archiv f. d. Eisenhüttenwesen, 1936/37, Heft 11, 12 u. $1937 / 38$, Hefte $1-5$. 